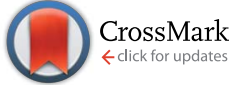

Cite this: RSC Adv., 2017, 7, 6467
Received 6th September 2016 Accepted 7th January 2017

DOI: $10.1039 / \mathrm{c} 6 \mathrm{ra22297h}$

www.rsc.org/advances

\section{Three-dimensional nitrogen and boron codoped graphene for carbon dioxide and oils adsorption}

\begin{abstract}
Ying Liu, Minghui Xiang* and Li Hong
Three-dimensional heteroatom-doped graphene macroporous structures possess superior features, such as the large pore volume, numerous surface active sites and the high specific surface area. These properties are useful for the preparation of high-performance adsorbents. We introduce a facile synthesis route for the preparation of three-dimensional nitrogen and boron codoped graphene aerogels (BN-GAs) via a solvothermal method at $180{ }^{\circ} \mathrm{C}$ for $6 \mathrm{~h}$. The BN-GAs possess mesostructures with $2.5-11 \mathrm{~nm}$ pores, a high surface area $\left(169.9 \mathrm{~m}^{2} \mathrm{~g}^{-1}\right)$, and contain nitrogen and boron. Based on the unique feature of the large specific surface area and the high nitrogen and boron contents, the BN-GAs show a high $\mathrm{CO}_{2}$ capture of $2.1-2.9 \mathrm{mmol} \mathrm{g}^{-1}$ (273 K, $1.0 \mathrm{bar}$ ) and excellent absorption capacities of up to $23 \mathrm{~g} \mathrm{~g}^{-1}$ for different oils and solvents. These results suggest that the BN-GAs may serve as a potential adsorbent for $\mathrm{CO}_{2}$ and oil leakage capture.
\end{abstract}

\section{Introduction}

Water pollution and global warming are the main environmental problems that challenge humanity. Water pollution is caused mainly by frequent oil and chemical solvent leakages. Three major measures have been used to address oil spillage and chemical solution leakage accidents: chemical methods (in situ burning), physical methods (various adsorbents) ${ }^{\mathbf{1 , 2}}$ and biological methods (biodegradation). ${ }^{3,4}$ However, burning may cause secondary pollution, and biodegradation suffers from intrinsic limitations, including a high cost and a long operational cycle. Solid adsorbents are of low cost and are easy to maintain, and thus, exhibit important potential in practical applications. Global warming is caused by greenhouse gas (carbon dioxide $\left(\mathrm{CO}_{2}\right)$, methane $\left(\mathrm{CH}_{4}\right)$, nitrous oxide $\left(\mathrm{N}_{2} \mathrm{O}\right)$, hydrofluorocarbons (HCFs)) emissions. $\mathrm{CO}_{2}$ that is derived from fossil fuel combustion is the most important greenhouse gas. Stabilizing $\mathrm{CO}_{2}$ levels in the atmosphere and establishing an efficient $\mathrm{CO}_{2}$ capture and sequestration technology is of vital significance. $\mathrm{CO}_{2}$ capture measures include mainly solid adsorbent adsorption and alkali solution adsorption. ${ }^{5-8} \mathrm{CO}_{2}$ adsorption by using alkali solutions is the most mature technology of the actual applications, but it exhibits intrinsic limitations, including energy consumption costs, operational safety, and equipment service life. ${ }^{9}$ Therefore, physical adsorption is also the best option to solve this problem.

Traditional solid absorbents consist of activated carbon, ${ }^{\mathbf{1 0}}$ metal-organic frameworks, ${ }^{\mathbf{1 1}, \mathbf{1 2}}$ mesoporous silica/carbon, ${ }^{\mathbf{1 3 , 1 4}}$ and zeolites, ${ }^{\mathbf{1 5 - 1 7}}$ and have been studied for $\mathrm{CO}_{2}$ capture and the

School of Environmental and Chemical Engineering, Shanghai University, Shanghai, 200444, China. E-mail: xiangmh@shu.edu.cn removal of oil after spillage. However, the high cost and inconvenience of recovery restricts the industrial, large-scale applications of zeolite materials. Activated carbon can overcome these weaknesses but it has a low adsorption capacity and a poor selectivity for the uptake of $\mathrm{CO}_{2}$ and spilled oils. Metalorganic framework materials exhibit a much higher capture capacity and selectivity than the two former adsorbents. The synthetic polymer process is complicated and their ecological impact remains unclear. Hence, it is critical to develop environmentally friendly $\mathrm{CO}_{2}$ and oil sorbents with a high sorption capacity, selectivity, and good recyclability.

Graphene, which consists of a single layer of carbon atoms that are packed tightly into a two-dimensional sheet of $\mathrm{sp}^{2}$ hybridized carbon, has been developed extensively in recent decades because of its extraordinary electron mobility, good mechanical properties, and thermal conductivity. ${ }^{18}$ Selfassembled graphene oxide (GO) with different functional materials to synthesize multifunctional graphene-based aerogels with synergistic performance, such as inorganic nanoparticles $\left(\mathrm{Fe},{ }^{19} \mathrm{Co},{ }^{20} \mathrm{Ni},{ }^{21}\right)$ doped graphene aerogels, graphene/ carbon nanotube composite aerogels, graphene/polymers (polyaniline (PANI), ${ }^{22}$ polyvinylidene fluoride (PVDF), ${ }^{23}$ polystyrene $\left.(\mathrm{PS}){ }^{24}\right)$ composite aerogels, and heteroatom $\left(\mathrm{N},{ }^{25} \mathrm{~B},{ }^{26,27} \mathrm{~S}^{28}\right)$ doped graphene aerogels have attracted significant attention because of their applications in environmental remediation, supercapacitors, hydrogen storage, flexible electronics, and sensors. As a sorbent, heteroatom-doped graphene aerogels display excellent performance over traditional materials because of two advantages: (1) the inherent characteristics of graphene aerogels, such as a larger specific surface area, porosity, and low apparent density; ${ }^{27}$ (2) their ability to create adsorption active sites by heteroatoms or carbon atoms around 

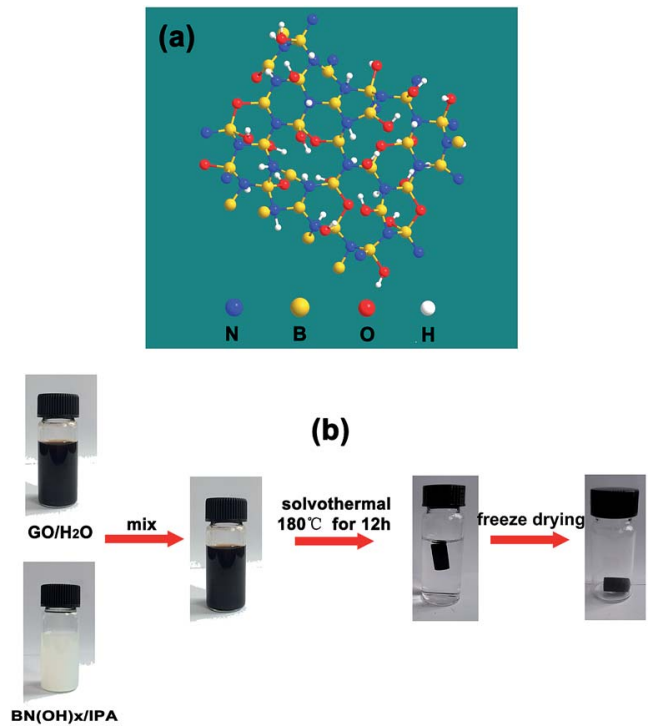

Fig. 1 (a) Atomic structure of $\mathrm{BN}(\mathrm{OH})_{x}$. (b) Schematic diagram illustrating the procedure to fabricate BN-GAs.

heteroatoms to promote the adsorption of acidic gas $\left(\mathrm{CO}_{2}\right.$, sulfur dioxide $\left.\left(\mathrm{SO}_{2}\right)\right)$ and their intrinsic hydrophobicity and oleophylic property. ${ }^{29,30}$ Hydroxylated boron nitride $\left(\mathrm{BN}(\mathrm{OH})_{x}\right)$ materials are structural analogues of graphene twodimensional materials in which $\mathrm{C}$ atoms are replaced by alternating boron $(\mathrm{B})$ and nitrogen $(\mathrm{N})$ atoms and with surface functionalization with hydroxyl groups (Fig. 1a). ${ }^{31} \mathrm{The} \mathrm{BN}(\mathrm{OH})_{x}$ has been used to load anticancer drugs because of their high degree of hydroxylation. However, the use of $\mathrm{BN}(\mathrm{OH})_{x}$ as functional materials mixed with graphene to prepare graphenebased aerogel has never been reported.

Herein, we demonstrate an efficient method for the largescale synthesis of a novel heterostructure that is comprised of $\mathrm{BN}(\mathrm{OH})_{x}$ nanosheets that are interconnected with $\mathrm{N}$ and $\mathrm{B}$ codoped graphene aerogels (BN-GAs). The advantages brought by the introduction of $\mathrm{BN}(\mathrm{OH})_{x}$ can be summarized as follows: (a) $\mathrm{BN}(\mathrm{OH})_{x}$ acts as the swelling agent to effectively prevent GO from restacking during the solvothermal process, thus producing a large pore volume. (b) The doping of nitrogen and boron atoms destroys the electrical neutrality of carbon materials and the uneven distribution of the charge, which enables the surface of the composites produce the adsorption active site. These advantages impart the BN-GAs with excellent adsorption capacity towards $\mathrm{CO}_{2}$ and oils. Fig. $1 \mathrm{~b}$ shows that the BN-GAs are prepared by using a one-step solvothermal method, during which the reduction of GO (rGO) and the doping of nitrogen and boron is achieved simultaneously.

\section{Experimental section}

\subsection{Materials}

Graphite powder $(99.9 \mathrm{wt} \%$, average particle size: $2 \mu \mathrm{m}$, Adamas), cyanoguanidine (99 wt\%, Adamas), boric acid (99 wt\%, Greagent), concentrated sulfuric acid, concentrated nitric acid, potassium permanganate, hydrogen peroxide, hydrochloric acid and other chemicals were obtained from Sinopharm Chemical Reagent Company. All chemicals were purchased and used directly without any further purification.

\subsection{Synthesis of GO}

GO was prepared from natural graphite flakes using a modified Hummers' method. ${ }^{29}$

\subsection{Synthesis of $\mathrm{BN}(\mathrm{OH})_{x}$}

$\mathrm{BN}(\mathrm{OH})_{x}$ was prepared via thermal substitution process. ${ }^{31}$ In a typical synthesis, cyanoguanidine was pyrolysis in a tubular

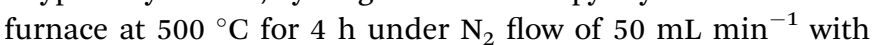
a ramp rate of $2.2^{\circ} \mathrm{C} \mathrm{min}^{-1}$ and nature cool to room temperature, and a yellow solid $\left(\mathrm{g}-\mathrm{C}_{3} \mathrm{~N}_{4}\right)$ was obtained. Then $3 \mathrm{~g} \mathrm{~g}-\mathrm{C}_{3} \mathrm{~N}_{4}$ powders and $0.9 \mathrm{~g}$ boric acid were dissolved in $100 \mathrm{~mL}$ deionized water, ultrasonic dispersion for 1 hour. It was then vaporized at $100{ }^{\circ} \mathrm{C}$ in air for several hours, and a mixture of well mixed g- $\mathrm{C}_{3} \mathrm{~N}_{4} /$ boric acid was obtained. The mixture was pyrolysis in a tubular furnace at $800{ }^{\circ} \mathrm{C}$ for $1 \mathrm{~h}$ under $\mathrm{N}_{2}$ flow of $50 \mathrm{~mL}$ $\mathrm{min}^{-1}$ with a ramp rate of $3 .{ }^{\circ} \mathrm{C} \mathrm{min}^{-1}$ and cool naturally to room temperature to obtain $\mathrm{BN}(\mathrm{OH})_{x}$.

\subsection{Synthesis of BN-GAs}

BN-GAs were prepared by a combined solvothermal assembly and freeze-drying process. In a typical procedure, a $10 \mathrm{~mL} \mathrm{GO}$ $\left(4 \mathrm{mg} \mathrm{mL}^{-1}\right)$ aqueous dispersion and a $10 \mathrm{~mL} \mathrm{BN}(\mathrm{OH})_{x}(2 \mathrm{mg}$ $\mathrm{mL}^{-1}$ ) isopropanol dispersion were treated by sonication for 30 min, followed by intimate mixing with mild ultrasound for $10 \mathrm{~min}$. The resulting stable suspension was sealed in a Teflonlined autoclave, and was treated solvothermally at $180{ }^{\circ} \mathrm{C}$ for $6 \mathrm{~h}$. A black cylinder-like organogel was produced and washed with deionized water several times to remove the isopropanol. Finally, the corresponding hydrogel was freeze overnight, followed by vacuum drying at $-60^{\circ} \mathrm{C}$ for $72 \mathrm{~h}$, then the aerogel $\mathrm{BN}$ $\mathrm{GA}_{X-Y}$ was obtained, where $X-Y$ is the mass ratio of $\mathrm{GO}$ to $\mathrm{BN}(\mathrm{OH})_{x}$. For comparison, GA (undoped) was also prepared using the same procedure.

\subsection{Materials characterization}

Photographs of the BN-GA materials were recorded using a COOLPIX S260 digital camera (Nikon, Japan). The morphology and microstructure were examined using S-4800 field-emission scanning electron microscopy (FE-SEM, Hitachi, Japan). Transmission electron microscopy (TEM) measurements were performed on an EOL-2100 (JEOL, Japan) electron microscope at an operating voltage of $200 \mathrm{kV}$. Atomic force microscopy (AFM) views were obtained using a Dimension 3100 (Vecco, USA) microscope. Powder X-ray diffraction (XRD) measurements were carried out on a D/max-2200/PC (Rigaku, Japan) with $\mathrm{Cu} \mathrm{K} \alpha \lambda=1.54 \AA$, a voltage of $40 \mathrm{kV}$ and a current of $40 \mathrm{~mA}$. Raman spectra were obtained using a SENTERRA instrument (Bruker, Germany) with $532 \mathrm{~nm}$ line of Ar-ion laser and approximately $5 \mathrm{~mW}$ power. The chemical nature of the composites was characterized via X-ray photoelectron spectroscopy (XPS) data that were acquired using an AXIS Ultra ${ }^{\text {DLD }}$ 
apparatus (Shimadzu-Kratos, Japan). Monochromatic Al K $\alpha$ Xray $(h \nu=1486.6 \mathrm{eV})$ was used for analysis, with a photoelectron takeoff angle of $90^{\circ}$ to the surface plane. The textural characteristics were quantified by measuring the $\mathrm{N}_{2}$ adsorption/ desorption isotherms at $-196{ }^{\circ} \mathrm{C}$ in a $3 \mathrm{H}-2000 \mathrm{PM} 2$ specific surface \& pore size analysis instrument (Beishide, China). All samples were outgassed at $150{ }^{\circ} \mathrm{C}$ under vacuum for $6 \mathrm{~h}$ prior to the $\mathrm{N}_{2}$ adsorption measurements. The specific surface area was determined by using the Brunauer-Emmett-Teller (BET) model for the $\mathrm{N}_{2}$ adsorption data in the relative pressure $\left(p / p_{0}\right)$ range of 0.05-0.20. The total pore volume $\left(V_{\text {total }}\right)$ was estimated from the amount of $\mathrm{N}_{2}$ adsorbed at $p / p_{0} \sim 0.99$, whereas the mesopore volume $\left(V_{\text {meso }}\right)$ and pore size distribution were calculated using the Barrett-Joyner-Halenda model.

\subsection{Gas adsorption measurements}

The $\mathrm{CO}_{2}$ adsorption equilibrium and kinetics of the as-prepared materials were measured volumetrically in a 3H-2000PM2 specific surface and pore-size analysis instrument. The adsorption isotherms were recorded at 0 and $25^{\circ} \mathrm{C}$, and up to 1 bar. The adsorption temperature was controlled by using a Dewar bottle with a circulating jacket that was connected to a thermostatic bath using water as the coolant. Approximately $100 \mathrm{mg}$ of adsorbent sample was used in the adsorption studies. Before each adsorption experiment, the samples were degassed at $150{ }^{\circ} \mathrm{C}$ under vacuum for $6 \mathrm{~h}$ to remove any moisture and organics. $\mathrm{N}_{2}$ adsorption isotherms at $25{ }^{\circ} \mathrm{C}$ were measured using an identical procedure. Ultrahigh-purity (99.99\%) gas sources were used. The expected experimental uncertainties in the amounts adsorbed, as estimated using error propagation in all the measured variables, was $0.02 \mathrm{mmol} \mathrm{g}^{-1}$.

\subsection{Oil absorption experiments}

The absorption capacity of graphene aerogel for various oils and organic solvents was determined by mass measurement. Firstly, the initial sample mass, $W_{\mathrm{i}}$, was determined. The sample was placed in different oils or organic solvents. After samples and surface oils or solvents were removed with filter paper, the sample was weighed and its mass, $W_{\mathrm{f}}$, was recorded. The oil absorption capacity $(Q)$ was calculated from:

$$
Q=\left(W_{\mathrm{f}}-W_{\mathrm{i}}\right) / W_{\mathrm{i}}
$$

\section{Results and discussion}

\subsection{Morphology and characterization}

The three-dimensional (3D) morphology of GA and BN-GA samples was confirmed by SEM and TEM. The GA sample had a very smooth surface with relatively small pore structure (Fig. 2a-c). In contrast, the $\mathrm{BN}_{-\mathrm{GA}_{2-1}}$ sample showed an interconnected framework of graphene nanosheets with a porous structure (Fig. 3a). Furthermore, Fig. $3 \mathrm{~b}$ exhibited that the $\mathrm{BN}$ $\mathrm{GA}_{2-1}$ sample had a well stacked layer structure, and had a considerable number of pore structures in the wall layers. Fig. $3 \mathrm{c}$ showed the morphology of $\mathrm{BN}^{-\mathrm{GA}_{2-1}}$ with a rough
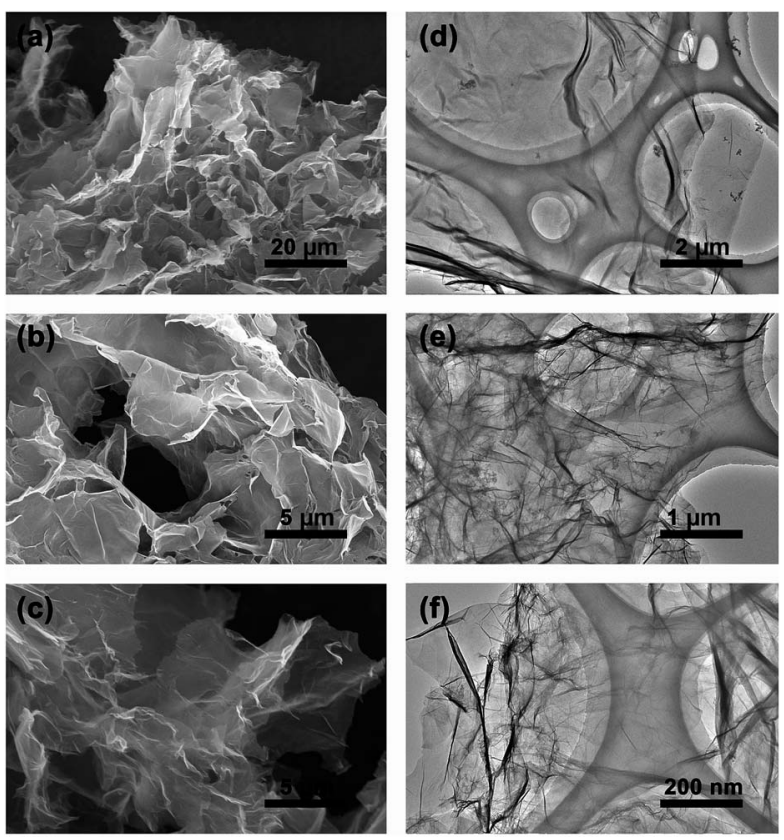

Fig. 2 (a, b, c) SEM and (d, e, f) TEM images of the GA.

surface, which was beneficial to improvement the adsorption capacity of the material. The TEM images indicated $\mathrm{BN}-\mathrm{GA}_{2-1}$ sample had more disordered packing structure with respect to GA (Fig. 2d-f and 3d, e), which indicated that the introduction of $\mathrm{BN}(\mathrm{OH})_{x}$ made the graphene sheets stacking more disordered and generated more pore structure. Fig. 3f showed the $\mathrm{BN}(\mathrm{OH})_{x}$ had a nanoscale lamellar structure.
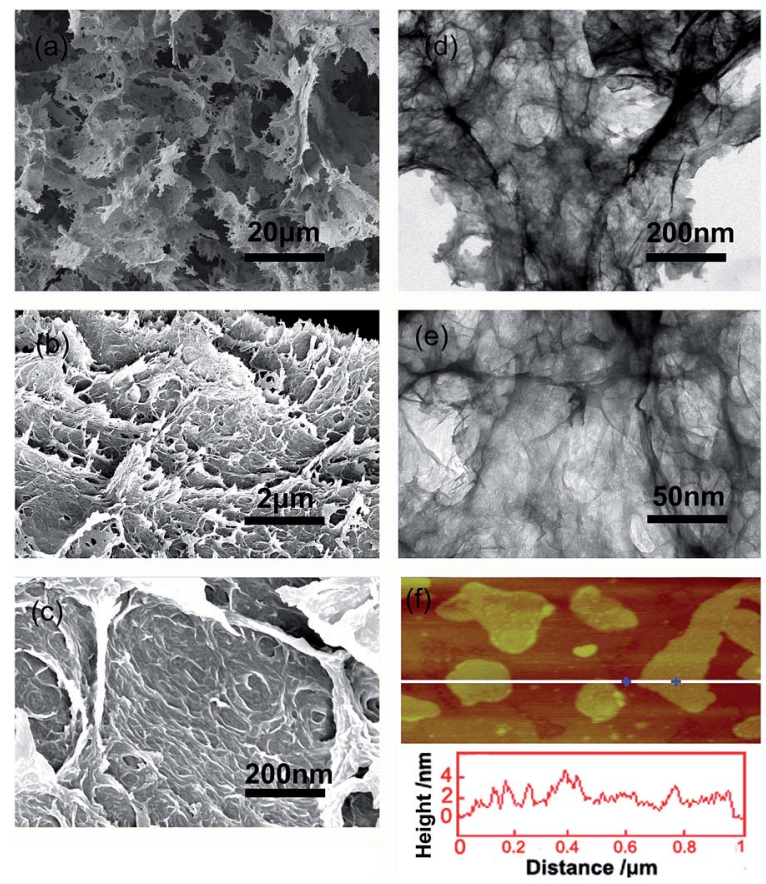

Fig. 3 (a, b, c) SEM and (d, e) TEM images of the BN-GA ${ }_{2-1}$ architecture. (f) AFM height image of the $B N(O H)_{x}$ aqueous suspension $\left(0.05 \mathrm{mg} \mathrm{mL}^{-1}\right)$. 
The $\mathrm{N}_{2}$ adsorption isotherm was a type-IV isotherm based on a significant hysteresis loop, which indicated that BN-GAs possessed a typical mesoporous structure (Fig. 4a). From the

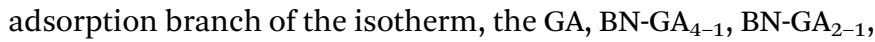
and $\mathrm{BN}-\mathrm{GA}_{1-1}$ specific surface areas were 52.3, 65.7, 112.4, and $169.9 \mathrm{~m}^{2} \mathrm{~g}^{-1}$ as calculated by a multi-point BET method, and the most probable pore width was $2.5-11 \mathrm{~nm}$ as calculated using the Barrett-Joyner-Halenda model. The pore-width distribution was concentrated in the range of a typical mesoporous structure (Fig. 4b). It was speculated that a mesoporous structure with a pronounced distribution of 2.5-11 nm appeared on the surface of the neighboring stacked graphene nanosheets on the BN-GAs. The total pore volumes of GA, BN$\mathrm{GA}_{4-1}, \mathrm{BN}-\mathrm{GA}_{2-1}$, and $\mathrm{BN}-\mathrm{GA}_{1-1}$, for pore widths ranging from 2 to $167 \mathrm{~nm}$, were $0.94,1.04,1.61$, and $2.21 \mathrm{~cm}^{3} \mathrm{~g}^{-1}$, respectively (Table 1). Our experimental data indicated that the specific surface area of the $\mathrm{BN}^{-\mathrm{GA}_{1-1}}$ was $169.9 \mathrm{~m}^{2} \mathrm{~g}^{-1}$, which was substantially higher than that of the raw GAs and could be attributed to the presence of $\mathrm{BN}(\mathrm{OH})_{x}$ sheets in the composite. The large pore volumes and specific surface areas of BN-GAs should guarantee the adsorption performance.

To confirm that the $\mathrm{BN}(\mathrm{OH})_{x}$ was doped in the BN-GAs during the solvothermal process, we obtained FTIR, XPS, XRD and Raman spectra. The FTIR data was shown in Fig. 5a. For $\mathrm{BN}-800-1$, the broad band at $3425 \mathrm{~cm}^{-1}$ was attributed to $\mathrm{O}-\mathrm{H}$ stretching vibrations of hydroxyl groups. The peaks at 1399 and $781 \mathrm{~cm}^{-1}$ belonged to stretching and bending modes of B-N vibrations, respectively. ${ }^{32}$ For the GO, the IR absorption peaks at 1622 and $1080 \mathrm{~cm}^{-1}$ corresponded to $\mathrm{C}=\mathrm{C}$ and $\mathrm{C}-\mathrm{O}$ stretching vibrations, respectively. ${ }^{32,33}$ The IR adsorption peak at 1389 $\mathrm{cm}^{-1}$ due to the $\mathrm{O}-\mathrm{H}$ deformation vibration. ${ }^{34}$ Obviously, the $\mathrm{B}-\mathrm{N}$ bending vibration at $786 \mathrm{~cm}^{-1}$ appeared in all $\mathrm{BN}-\mathrm{GA}_{X}$ samples. The B-N stretching vibration at $1399 \mathrm{~cm}^{-1}$ might overlap with the peak position of the $\mathrm{O}-\mathrm{H}$ deformation vibration in the reduction of graphene oxide. Furthermore, the other characteristic absorption peaks of the reduction of graphene oxide were also found in all BN-GA samples, suggesting the successful doping of nitrogen and boron.

XPS measurements of $\mathrm{GA}, \mathrm{BN}(\mathrm{OH})_{x}$, and ${\mathrm{BN}-\mathrm{GA}_{1-1}}_{\text {were }}$ shown in Fig. 5b-h. We observed two additional peaks with binding energies of $191.1 \mathrm{eV}$ (B 1s) and $399.3 \mathrm{eV}$ (N 1s), ${ }^{25-27,30,31}$ which confirmed the presence of boron and nitrogen, as shown in the XPS survey spectra of the $\mathrm{BN}^{-\mathrm{GA}_{1-1}}$ sample (Fig. 5b). Fig. 5c showed the $\mathrm{C} 1 \mathrm{~s}$ spectrum of GA which exhibited four peaks of $\mathrm{C}=\mathrm{C}(284.8 \mathrm{eV}), \mathrm{C}-\mathrm{O}(286.7 \mathrm{eV}), \mathrm{C}=\mathrm{O}(287.2 \mathrm{eV})$ and $\mathrm{O}-\mathrm{C}=\mathrm{O}(288.2 \mathrm{eV}) .{ }^{19,30}$ Fig. $5 \mathrm{e}$ showed the $\mathrm{N}$ 1s spectrum of $\mathrm{BN}(\mathrm{OH})_{x}$ which exhibited two peaks of $\mathrm{B}_{3} \mathrm{~N}(398.6 \mathrm{eV})$ and $\mathrm{B}_{3} \mathrm{NH}$

Table 1 Textural properties of GA and BN-GAs

\begin{tabular}{lll}
\hline & \multicolumn{2}{l}{ Textual properties } \\
\cline { 2 - 3 } Sample & $S_{\text {BET }}\left(\mathrm{m}^{2} \mathrm{~g}^{-1}\right)$ & $V_{\text {total }}\left(\mathrm{cm}^{3} \mathrm{~g}^{-1}\right)$ \\
\hline GA & 52.3 & 0.94 \\
BN-GA $_{4-1}$ & 65.7 & 1.04 \\
BN-GA $_{2-1}$ & 112.4 & 1.61 \\
BN-GA $_{1-1}$ & 169.9 & 2.21
\end{tabular}
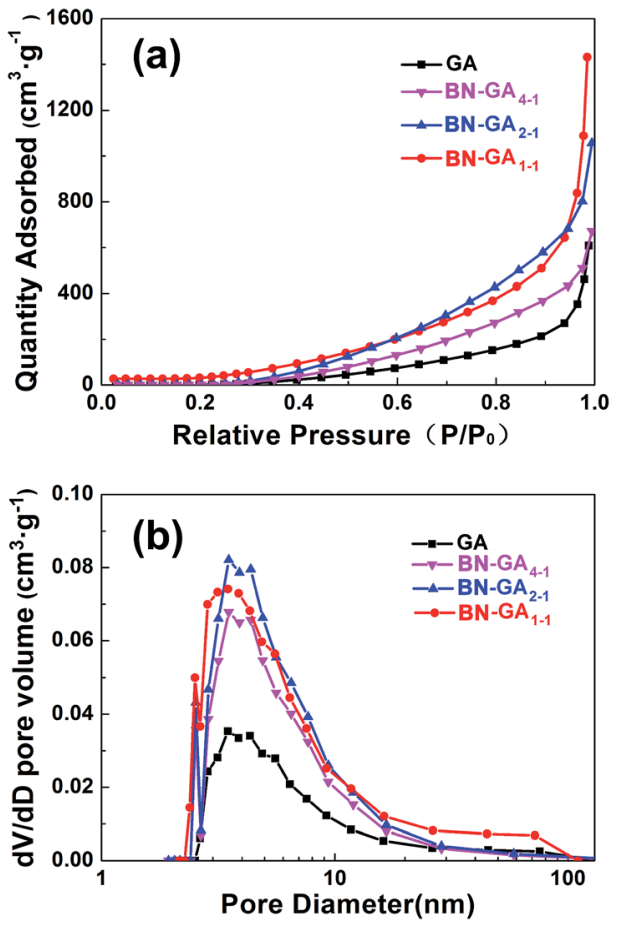

Fig. 4 (a) $\mathrm{N}_{2}$ sorption isotherms (b) $\mathrm{BJH}$ pore distribution of $\mathrm{GA}$ and BN-GAs.

$(400.2 \mathrm{eV})$. The B 1s spectrum of $\mathrm{BN}(\mathrm{OH})_{x}$ exhibited two peaks of $\mathrm{BN}_{3}(190.8 \mathrm{eV})$ and $\mathrm{N}_{3} \mathrm{~B}(\mathrm{OH})(191.8 \mathrm{eV})$, as shown in Fig. $5 \mathrm{~g} .{ }^{31}$ Four peaks $(284.3,284.9,286.8$ and $289.9 \mathrm{eV})$ in the $\mathrm{C}$ 1s spectrum of ${\mathrm{BN}-\mathrm{GA}_{1-1}}$ correspond to the $\mathrm{sp}^{2} \mathrm{C}$ and the chemical environment of carbon atoms bonded to carbon, nitrogen, and boron in graphene (Fig. 5b). ${ }^{30,35}$ The asymmetric $\mathrm{N}$ 1s XPS peak of $\mathrm{BN}_{-\mathrm{GA}_{1-1}}$ (Fig. 5f) could be fitted to four peaks of pyridinic $\mathrm{N}$ (398.1 eV), pyrrolic $\mathrm{N}(399.9 \mathrm{eV})$ graphitic $\mathrm{N}(402.6 \mathrm{eV})$, and $\mathrm{C}-\mathrm{N}-\mathrm{B}(399.3 \mathrm{eV}) .^{25,30,31}$ Two peaks at $190.8 \mathrm{eV}\left(\mathrm{B}-\mathrm{N}, \mathrm{BC}_{3}\right)$ and $192.1 \mathrm{eV}\left(\mathrm{BC}_{2} \mathrm{O}, \mathrm{BCO}_{2}\right)$ could be identified by fitting the $\mathrm{B} 1 \mathrm{~s}$ XPS

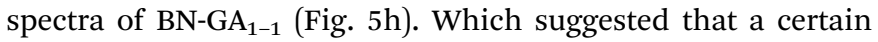
amount of boron was bonded to nitrogen as $\mathrm{B}-\mathrm{N}$, with carbon in the form of $\mathrm{B}-\mathrm{C}$, and with oxygen in the form of $\mathrm{B}-\mathrm{O}$, respectively. $^{30,31}$ The above spectral observation indicated the successful doping of $\mathrm{BN}(\mathrm{OH})_{x}$.

The XRD patterns indicated that the $\mathrm{BN}^{-\mathrm{GA}_{1-1}}$ contained rGO and $\mathrm{BN}(\mathrm{OH})_{x}$ (Fig. 6a). The weak peaks at 24.2 (002) and 43.1 (100) could be attributed to rGO, the disappearance of the peak at $11.0(001)$ that corresponded to GO indicated that the GO reduction was complete. ${ }^{36-38}$ Very weak graphene sheet peaks of $\mathrm{BN}_{-\mathrm{GA}_{1-1}}$ were detected, which suggested that graphene sheets had a highly disordered stacking with a low degree of graphitization because the $\mathrm{BN}(\mathrm{OH})_{x}$ sheets in the graphene sheets prevented the graphene sheets from restacking. ${ }^{36,39}$ The Raman spectra of GA and BN-GAs exhibited two typical peaks (D band and $\mathrm{G}$ band) and a small broad peak of a two-dimensional band (Fig. 6b). The D band at around $1346 \mathrm{~cm}^{-1}$ corresponded to the defects of the graphene, and the G-band at around 1580 $\mathrm{cm}^{-1}$ provided evidence for the existence of $\mathrm{sp}^{2}$-hybridized carbon atoms and ordered graphitic structure. ${ }^{2}$ The ratios of the 

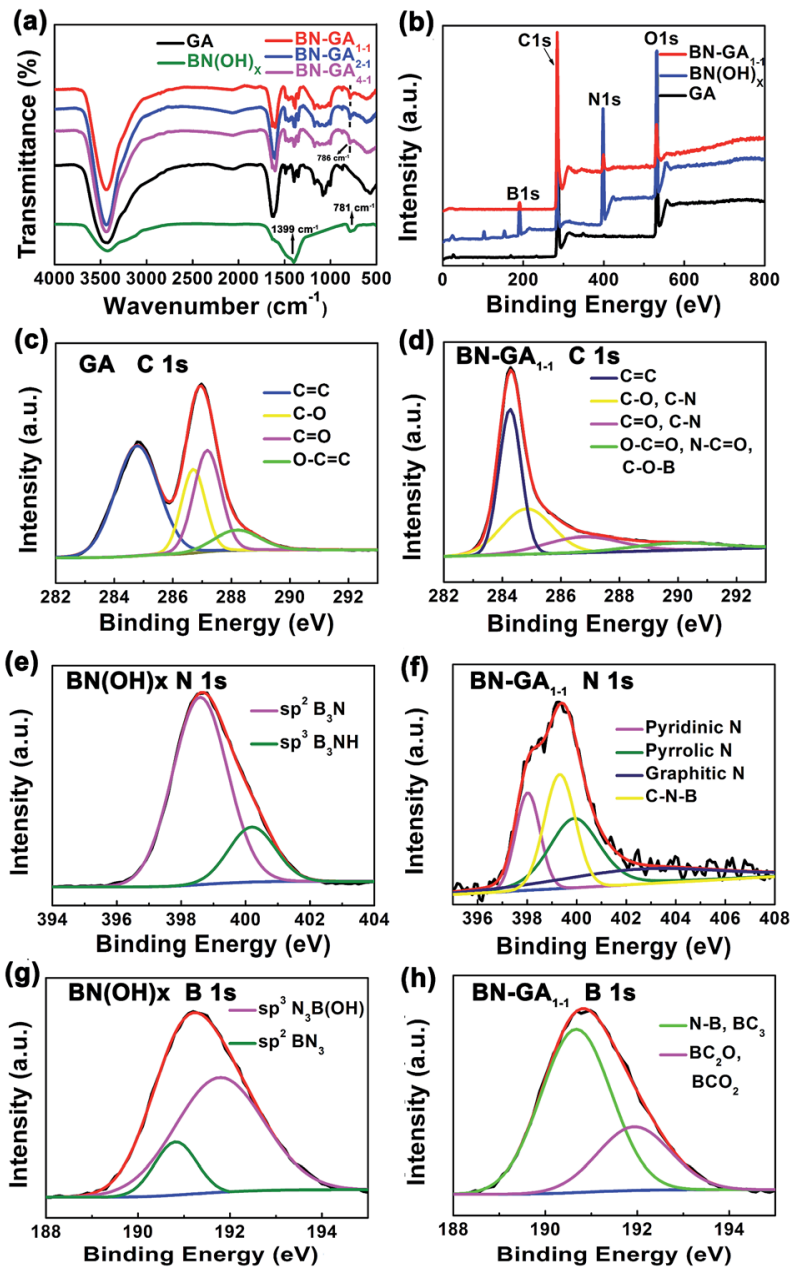

Fig. 5 (a) FTIR spectra of $B N(O H)_{x}, G A, B N-G A_{s}$. (b-h) XPS data of GA, $\mathrm{BN}(\mathrm{OH})_{x}$ and $\mathrm{BN}-\mathrm{GA}_{1-1}$.

$\mathrm{D}$ band to $\mathrm{G}$ band integrated intensities $\left(I_{\mathrm{D}} / I_{\mathrm{G}}\right)$ were $1.05(\mathrm{GA})$,

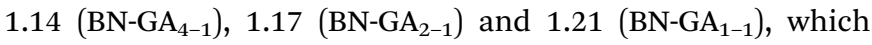
indicated the disordered degree of graphene increased with the increasing of $\mathrm{BN}(\mathrm{OH})_{x}$ doping amount. ${ }^{27,37,40}$

\subsection{Oil and organic solvents capture capacity}

BN-GAs are hydrophobic and have a high porosity, so they should have excellent absorption capacities for oil spills and organic contaminants. ${ }^{\mathbf{4 1 - 4 4}}$ The adsorption properties of the monoliths were evaluated for a range of organic solvents and oils. The $\mathrm{BN}^{-\mathrm{GA}_{1-1}}$ exhibited a high and rapid absorption for dodecane (Fig. 7). Once it contacted an oil film (dodecane) dispersed on the water surface, the $\mathrm{BN}_{-\mathrm{GA}_{1-1}}$ absorbed the surrounding oil layer immediately to remove the oil film and gave rise to the emergence of a transparent water surface after a few seconds. The absorption capacities of the monoliths for different oils and solvents varied from 10 to 23 times their own weight, depending on the density and viscosity of the oils and organic solvents (Fig. 8). The excellent absorption capability could be attributed to the porous structure and large hydrophobic surface area of the reduced graphene and to the
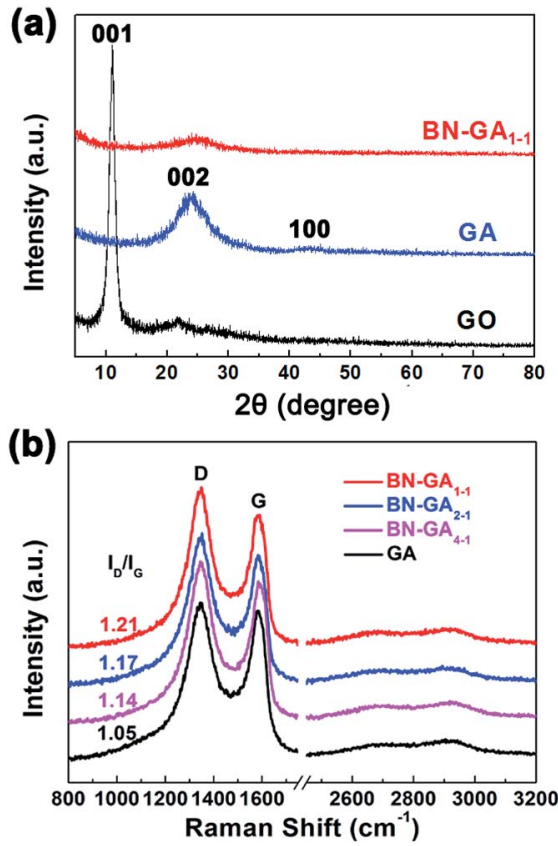

Fig. 6 (a) XRD patterns of the GO, GA and $B N-G_{1-1}$. (b) Raman spectra of the GA and BN-GAs.

abundant amount of adsorption active sites, which had a considerably larger nitrogen, boron, and hydroxyl group content. The adsorbed oils in the BN-GAs could be extracted by using an acetone solvent followed by drying, whereas absorbed organic solvents were removed readily by heating. Thus, the BNGAs could be used repeatedly in oil-water separation, water purity, and environmental protection.

\section{3 $\mathrm{CO}_{2}$ capture capacity}

The BN-GAs also have excellent absorption capacity for $\mathrm{CO}_{2}$. The $\mathrm{CO}_{2}$ adsorption isotherms of the as-prepared GA and the BN-GA samples at 0 and $25^{\circ} \mathrm{C}$ were shown in Fig. 9a and b, respectively. As expected, $\mathrm{CO}_{2}$ adsorption by the GA materials was dependent on their specific surface area, pore size, and adsorption active

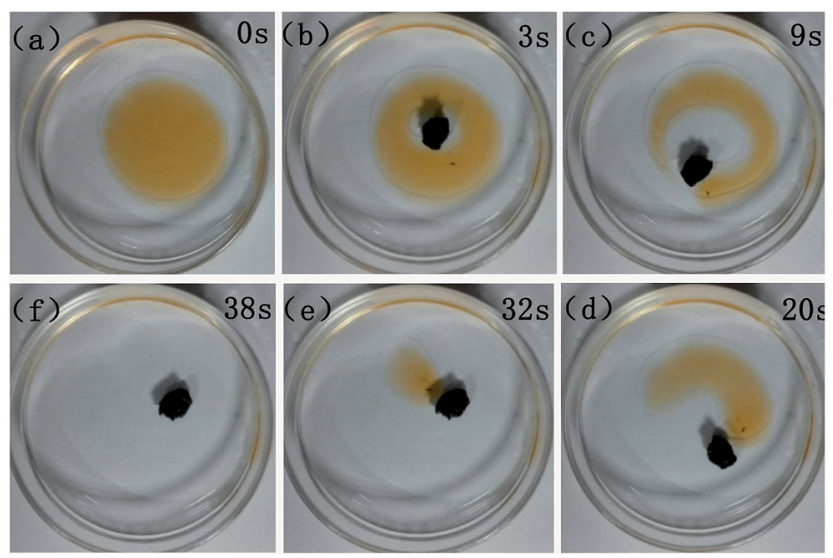

Fig. 7 Absorption of dodecane from water with $B N-G A_{1-1}$. The dodecane was dyed with Sudan red for clear observation. 


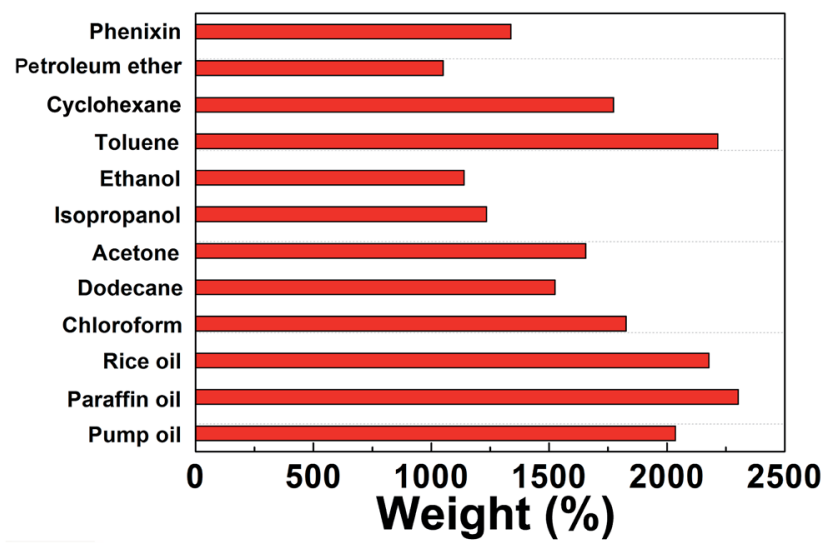

Fig. 8 Adsorption capacities of $\mathrm{BN}-\mathrm{GA}_{1-1}$ for various oils and organic solvents.
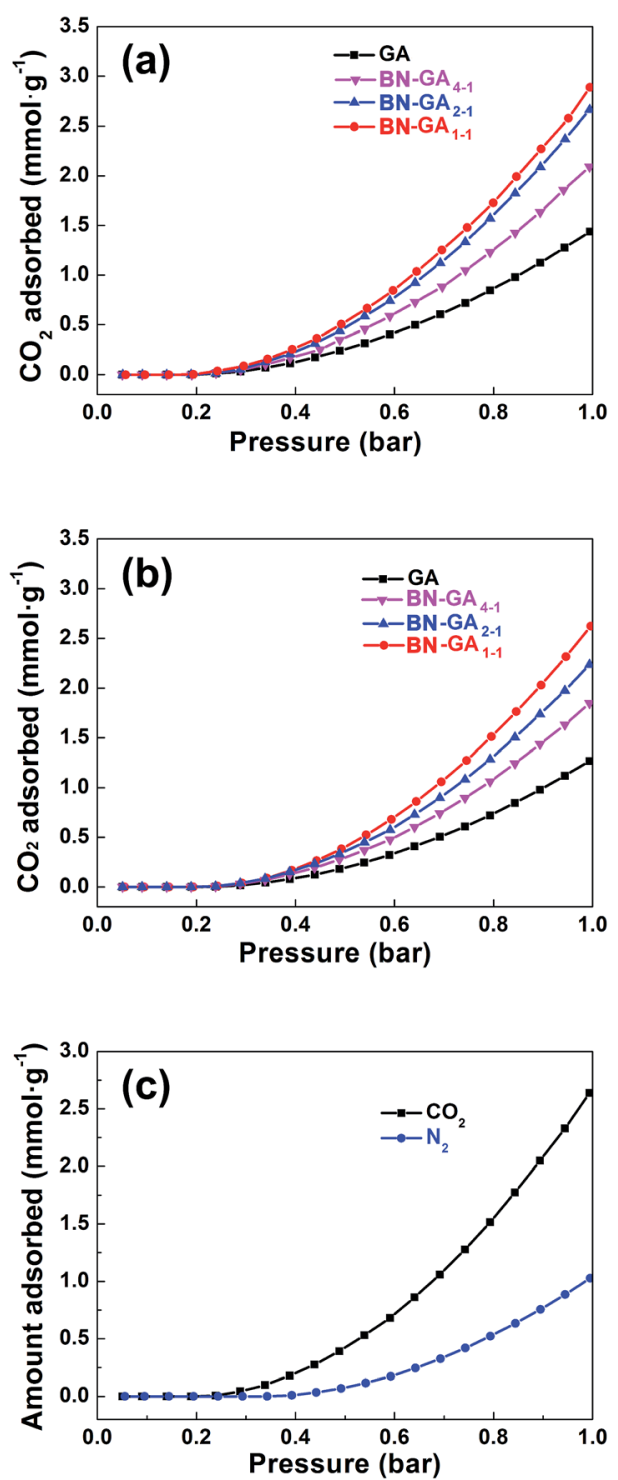

Fig. $9 \mathrm{CO}_{2}$ adsorption isotherms at (a) $0{ }^{\circ} \mathrm{C}$ and (b) $25^{\circ} \mathrm{C}$ for $\mathrm{GA}$ and $\mathrm{BN}-\mathrm{GAs}$, respectively. (c) $\mathrm{CO}_{2}$ and $\mathrm{N}_{2}$ adsorption isotherms of $\mathrm{BN}-$ $\mathrm{GA}_{1-1}$ at $25^{\circ} \mathrm{C}$.
Table $2 \mathrm{CO}_{2}$ capture capacities of the GA and BN-GAs at different adsorption temperatures and 1 bar

\begin{tabular}{lll}
\hline & \multicolumn{2}{l}{$\mathrm{CO}_{2}$ uptake, $\mathrm{mmol} \mathrm{g}^{-1}\left(\mathrm{mg} \mathrm{g}^{-1}\right)$} \\
\cline { 2 - 3 } Sample & $0{ }^{\circ} \mathrm{C}$ & $25{ }^{\circ} \mathrm{C}$ \\
\hline $\mathrm{GA}$ & $1.4(61.6)$ & $1.3(57.2)$ \\
$\mathrm{BN}-\mathrm{GA}_{4-1}$ & $2.1(92.4)$ & $1.8(79.2)$ \\
$\mathrm{BN}^{-G A}{ }_{2-1}$ & $2.7(118.8)$ & $2.2(96.8)$ \\
$\mathrm{BN}^{-G A} A_{1-1}$ & $2.9(127.6)$ & $2.6(114.4)$
\end{tabular}

site (Table 2). GA, due to its low specific surface area (52.3 $\mathrm{m}^{2} \mathrm{~g}^{-1}$ ) and rare adsorption active sites, showed the lowest $\mathrm{CO}_{2}$ adsorption capacity of 1.4 and $1.3 \mathrm{mmol} \mathrm{g}^{-1}$ at 0 and $25{ }^{\circ} \mathrm{C}$, respectively, whereas the BN-GA samples $\mathrm{CO}_{2}$ adsorption capacity at $0{ }^{\circ} \mathrm{C}$ and $25{ }^{\circ} \mathrm{C}$ was in the $2.1-2.9 \mathrm{mmol} \mathrm{g}^{-1}$ (61.6$\left.127.6 \mathrm{mg} \mathrm{g}^{-1}\right)$ and $1.8-2.6 \mathrm{mmol} \mathrm{g}^{-1}\left(57.2-114.4 \mathrm{mg} \mathrm{g}^{-1}\right)$ range, respectively. The $\mathrm{CO}_{2} / \mathrm{N}_{2}$ selectivity of $\mathrm{BN}^{-\mathrm{GA}_{1-1}}$ was calculated from the single component $\mathrm{CO}_{2}$ and $\mathrm{N}_{2}$ adsorption isotherms (Fig. 9c). BN-GA ${ }_{1-1}$ showed a $\mathrm{CO}_{2} / \mathrm{N}_{2}$ saturation pressure selectivity of 2.6. BN-GAs exhibit, relative to the GA sample, better $\mathrm{CO}_{2}$ uptake and excellent $\mathrm{CO}_{2} / \mathrm{N}_{2}$ selectivity. This is due to the $\mathrm{N}$, B codoped graphene aerogels with hydroxylated boron nitrides exhibit two specific characteristics that have a positive effect on $\mathrm{CO}_{2}$ adsorption. Indeed, the BN-GAs samples have a larger specific surface area, higher porosity, and more adsorption active sites, which contain a considerably larger nitrogen, boron, and hydroxyl group content.

As a stable and nontoxic carbon material, the aerogels will not have any adverse effect on human and environment, GA and its composites as the adsorption material has been a lot of reported. ${ }^{45}$ The initial synthesis of $\mathrm{BN}(\mathrm{OH})_{x}$ is used as a kind of safe, nontoxic, stable, biocompatible anticancer drug carrier. ${ }^{31}$ Thereby, BN-GAs which prepared by solvothermal method with GO and $\mathrm{BN}(\mathrm{OH})_{x}$ are safe, stable and nontoxic. In these threedimensional materials, the stacked rGO layers provided skeleton structure and the introduction of $\mathrm{BN}(\mathrm{OH})_{x}$ sheets increases the porosity, the surface roughness and the adsorption active sites. As for the process of $\mathrm{CO}_{2}$ and oils adsorption, it will not cause reactions to produce toxic and harmful substances. Meanwhile, BN-GAs have the advantages of operation safety, low energy consumption, easy maintenance and regeneration as a solid adsorbent, indicating excellent industrial application potentials.

\section{Conclusion}

In summary, we have synthesized self-assembled BN-GAs hybrids using a facile solvothermal reduction and freezedrying of $\mathrm{GO}$ and $\mathrm{BN}(\mathrm{OH})_{x}$ dispersions in a mixture of isopropanol and water. Because of the $\mathrm{BN}(\mathrm{OH})_{x}$ hybrid 3D macroporous structure and high surface area, the resulting BN-GAs show excellent adsorption performance for $\mathrm{CO}_{2}$, oil, and organic solvents and outstanding $\mathrm{CO}_{2} / \mathrm{N}_{2}$ selectivity, which may provide BN-GAs as a 3D porous structure for other efficient energy-storage and environmental protection devices. 


\section{Acknowledgements}

This work was supported by the National Sciences \& Technology Major Project of China (No. 2011ZX05011-004) and the National Nature Sciences Foundation of China (No. 41502122).

\section{Notes and references}

1 K. C. Kemp, H. Seema, M. Saleh, N. H. Le, K. Mahesh, V. Chandra and K. S. Kim, Nanoscale, 2013, 5, 3149.

2 C. Chen, R. Li, L. Xu and D. Yan, RSC Adv., 2014, 4, 17393.

3 R. M. Atlas and T. C. Hazen, Environ. Sci. Technol., 2011, 45, 6709.

4 K. Rahman, J. Thahira-Rahman, P. Lakshmanaperumalsamy and I. Banat, Bioresour. Technol., 2002, 85, 257.

5 A. B. Rao and E. S. Rubin, Environ. Sci. Technol., 2002, 36, 4467.

6 D. Camper, J. E. Bara, D. L. Gin and R. D. Noble, Ind. Eng. Chem. Res., 2008, 47, 8496.

7 J. E. Bara, D. E. Camper, D. L. Gin and R. D. Noble, Acc. Chem. Res., 2009, 43, 152.

8 C.-H. Yu, C.-H. Huang and C.-S. Tan, Aerosol Air Qual. Res., 2012, $12,745$.

9 C. Zhang, W. Song, Q. Ma, L.-J. Xie and X. Zhang, Energy Fuels, 2016, 30, 4181.

10 H. Yang, M. Gong and Y. Chen, J. Nat. Gas Chem., 2011, 20, 460.

11 Q. Yang, S. Vaesen, F. Ragon, A. D. Wiersum, D. Wu, A. Lago, T. Devic, C. Martineau, F. Taulelle and P. L. Llewellyn, Angew. Chem., Int. Ed., 2013, 52, 10316.

12 C. Yang, U. Kaipa, Q. Z. Mather, X. Wang, V. Nesterov, A. F. Venero and M. A. Omary, J. Am. Chem. Soc., 2011, 133, 18094.

13 G.-P. Hao, W.-C. Li, D. Qian, G.-H. Wang, W.-P. Zhang, T. Zhang, A.-Q. Wang, F. Schüth, H.-J. Bongard and A.-H. Lu, J. Am. Chem. Soc., 2011, 133, 11378.

14 I. Tan, A. Ahmad and B. Hameed, J. Hazard. Mater., 2009, 164, 473.

15 J.-S. Lee, J.-H. Kim, J.-T. Kim, J.-K. Suh, J.-M. Lee and C.-H. Lee, J. Chem. Eng. Data, 2002, 47, 1237.

16 F. Su, C. Lu, S.-C. Kuo and W. Zeng, Energy Fuels, 2010, 24, 1441.

17 G. J. Suppes, M. A. Dasari, E. J. Doskocil, P. J. Mankidy and M. J. Goff, Appl. Catal., A, 2004, 257, 213.

18 X. Huang, Z. Yin, S. Wu, X. Qi, Q. He, Q. Zhang, Q. Yan, F. Boey and H. Zhang, Small, 2011, 7, 1876.

19 S. Yang, X. Song, P. Zhang, J. Sun and L. Gao, Small, 2014, 10, 2270.

20 R. Wang, C. Xu, J. Sun, L. Gao and H. Yao, ACS Appl. Mater. Interfaces, 2014, 6, 3427.
21 L. Ren, K. S. Hui and K. N. Hui, J. Mater. Chem. A, 2013, 1, 5689.

22 Y.-C. Yong, X.-C. Dong, M. B. Chan-Park, H. Song and P. Chen, ACS Nano, 2012, 6, 2394.

23 R. Li, C. Chen, J. Li, L. Xu, G. Xiao and D. Yan, J. Mater. Chem. A, 2014, 2, 3057.

24 Y. Lin, G. J. Ehlert, C. Bukowsky and H. A. Sodano, ACS Appl. Mater. Interfaces, 2011, 3, 2200.

25 Y. Zhao, C. Hu, Y. Hu, H. Cheng, G. Shi and L. Qu, Angew. Chem., Int. Ed., 2012, 124, 11533.

26 Y. Su, Y. Zhang, X. Zhuang, S. Li, D. Wu, F. Zhang and X. Feng, Carbon, 2013, 62, 296.

27 Z. S. Wu, A. Winter, L. Chen, Y. Sun, A. Turchanin, X. Feng and K. Müllen, Adv. Mater., 2012, 24, 5130.

28 J. Liang, Y. Jiao, M. Jaroniec and S. Z. Qiao, Angew. Chem., Int. Ed., 2012, 51, 11496.

29 W. S. Hummers Jr and R. E. Offeman, J. Am. Chem. Soc., 1958, 80, 1339.

30 M. Sevilla, P. Valle-Vigón and A. B. Fuertes, Adv. Funct. Mater., 2011, 21, 2781.

31 Q. Weng, B. Wang, X. Wang, N. Hanagata, X. Li, D. Liu, X. Wang, X. Jiang, Y. Bando and D. Golberg, ACS Nano, 2014, 8, 6123.

32 H. Yang, H. Zhu, M. M. Hendrix, N. J. Lousberg, W. G. De, A. C. Esteves and J. H. Xin, Adv. Mater., 2013, 25, 1150.

33 S. Tao, Y. Wang and Y. An, J. Mater. Chem., 2011, 21, 11901.

$34 \mathrm{H}$. Hu, Z. Zhao, W. Wan, Y. Gogotsi and J. Qiu, Adv. Mater., 2013, 25, 2219.

35 J. Zhou, Z. Zhang, W. Xing, J. Yu, G. Han, W. Si and S. Zhuo, Electrochim. Acta, 2015, 153, 68.

36 S. Chowdhury and R. Balasubramanian, Ind. Eng. Chem. Res., 2016, 55, 7906.

37 Y. Xu, K. Sheng, C. Li and G. Shi, ACS Nano, 2010, 4, 4324.

38 M. Z. Iqbal and A. A. Abdala, RSC Adv., 2013, 3, 24455.

39 S. Yang, X. Song, P. Zhang, J. Sun and L. Gao, Small, 2014, 10, 2270.

40 L. Xu, G. Xiao, C. Chen, R. Li, Y. Mai, G. Sun and D. Yan, J. Mater. Chem. A, 2015, 3, 7498.

41 S. Kabiri, D. N. Tran, T. Altalhi and D. Losic, Carbon, 2014, 80, 523.

42 Y. He, Y. Liu, T. Wu, J. Ma, X. Wang, Q. Gong, W. Kong, F. Xing, Y. Liu and J. Gao, J. Hazard. Mater., 2013, 260, 796.

43 X. Song, L. Lin, M. Rong, Y. Wang, Z. Xie and X. Chen, Carbon, 2014, 80, 174.

44 X. Gui, Z. Zeng, Z. Lin, Q. Gan, R. Xiang, Y. Zhu, A. Cao and Z. Tang, ACS Appl. Mater. Interfaces, 2013, 5, 5845.

45 M. Yusuf, F. M. Elfghi, S. A. Zaidi, E. C. Abdullah and M. A. Khan, $R S C A d v ., 2015$, 5, 50392. 